\title{
ROLE OF INTERLEUKIN-17 IN THE DEVELOPMENT OF HEPATOCELLULAR CARCINOMA IN HEPATITIS C VIRUS LIVER CIRRHOSIS
}

\section{Ayman Fathy Elsayed, Esam Nasr Mohammed, Naglaa Ali Ali, Amani Mohammad Ibrahim . Internal Medicine Department; Zagazig University; Egypt.}

\section{ABSTRACT}

Background: The level of Interleukin-17 (IL-17) have been found in increased frequencies within certain tumors. However, their role in cancer biology remains controversial. This study aimed to clarify the role of IL-17 in hepatocellular carcinoma (HCC).

Subjects\& Methods: It included a total number of 81 subjects. They were divided into three groups: 27 subjects as control group, Group I (27 subjects HCV cirrhotic patients without HCC), Group II (27 subjects HCV cirrhotic patients with HCC). All patients included in this study were subjected to the following: Full clinical assessment, Complete blood picture, Liver function tests, Renal function tests, Coagulation profile , HCV Antibodies, HBs Ag , $\alpha$ fetoprotein and IL-17.

Results: our study reported statistical significance differences $(\mathrm{p}<0.001)$ between the three studied group in interleukin 17 level. The highest mean of IL 17 level were found in group 2 followed by group 1 and the control group had the lowest mean level.

Conclusion: IL-17 levels were increased with increasing liver disease progression and chronicity, IL-17 may play an important role in HCC immunopathogenesis in HCV cirrhotic patients. Also, its therapeutic application needs to be evaluated by in vivo studies in experimental animals aiming at future immunotherapy..

Keywords: Interleukin (IL)-17, HCV, Cirrhosis, HCC.

\section{INTRODUCTION}

$\mathbf{H}^{2}$ epatocellular carcinoma (HCC) is the fifth most common cancer and the third most common cause of cancer-related death globally ${ }^{[1]}$. In Egypt, hepatocellular carcinoma is the second most common cancer in men and the $6^{\text {th }}$ most common cancers in women. Hospitalbased studies from Egypt have reported an overall increase in the relative frequency of all liver-related cancers in Egypt, from approximately $4 \%$ in 1993 to $7.3 \%$ in $2003^{[2]}$.

Hepatitis C virus (HCV) is a serious worldwide health problem, with more than 170 million people infected globally. In the Egyptian population, up to $90 \%$ of $\mathrm{HCC}$ cases were attributed to HCV infection. ${ }^{[3]}$. Approximately $14 \%$ of the population in Egypt is infected with HCV and 7 million people are believed to suffer from a chronic liver disease ${ }^{[4]}$.

$\mathrm{HCV}$ establishes persistent infection in $70 \%$ of infected individuals, leading to chronic liver inflammation, fibrosis, and cirrhosis. ${ }^{[5]}$. The outcome of HCV infection is primarily dictated by the magnitude and character of the T-cell response to infection. CD4 T-cell responses play a critical role in the resolution of infection and impaired $\mathrm{HCV}$-specific CD4 Tcell responses are observed in chronic $\mathrm{HCV}^{[6]}$.

Interleukin (IL)-17-producing T-helper (Th)17 cells have been reported to trigger tissue inflammation and damage ${ }^{[7]}$ and there is accumulating evidence that Th17 cells are important contributors to hepatic inflammation and liver cirrhosis ${ }^{[8]}$.

Th17 cells and its signature cytokine, interleukin-17 (IL-17), have been found increased frequencies within certain tumors . ${ }^{[9]}$ However, the relationship between Th17 cells and tumor immunopathology has been controversial. ${ }^{[10]}$

Both beneficial and detrimental direct and indirect effects of IL-17 occurred in context and tumor system dependent manners. Transfection of IL-17 into tumor cells augmented the progression of the disease in nude mice via the effects on vascular endothelium and increased neoangiogenesis . ${ }^{[1]}$.

The aim of our study was to clarify the role of interleukin-17 in patients with end stage liver disease and hepatocellular carcinoma in $\mathrm{HCV}$ infected patients.

\section{Subjects \& Methods}

This study was carried out in Internal Medicine Department, Zagazig University Hospitals, Faculty of Medicine, Zagazig University.

\section{A)Subjects:}

The study included 54 cases with liver cirrhosis and HCV positive antibodies These patients were selected from Outpatient Clinics and Inpatient Wards of the Internal Medicine Department, Faculty of Medicine, Zagazig University. They were classified into two main 
groups according to presence or absence of HCC. In addition to 27 healthy subjects serving as controls. The control subjects were collected from healthy blood donors and relatives of the patients

\section{1)Control Group}

Included 27 healthy HCV negative subjects. They had negative markers for HBV and $\mathrm{HCV}$ infections, had no hepatic diseases and they were sex and age matched with patients. They were (15 males and 12 females), with age ranged from 39 years to 65 years with a mean values + SD $53.78 \pm 5.84$ years.

\section{2) Group I:}

Included 27 liver cirrhotic $\mathrm{HCV}$ positive patients without HCC (14 males and 13 females), with age ranged from 40 years to 66 years with a mean values + SD $54.33 \pm 7.37$ years.

\section{3) Group II:}

Included 27 liver cirrhotic $\mathrm{HCV}$ positive patients with HCC (12 males and 15 females), with age ranged from 44 years to 69 years with a mean values + SD $56.15 \pm 6.86$ years

\section{B) Methods of Study}

All subjects of the study were subjected to the following:-

Thorough history and full clinical examination:

Special emphasis on History of upper GIT bleeding, endoscopic intervention, Presence of jaundice and ascites and its degree,Hepatic encephalopathy and its grades, History of DM ,hypertension or smoking.

Laboratory investigations:

- Complete blood picture.

- Liver function tests.

- Renal function tests.

- PT, PTT and INR.

- $\mathrm{HCV}$ Antibodies and HBs Ag

- $\alpha$ fetoprotein

- IL-17 by ELISA technique ${ }^{[12]}$.

Kits(Human IL-17 Immunoassay Quantikine (B) ELISA) was provided by R\&D Systems company Minneapolis, MN 55413, USA.

\section{RESULTS}

Table (1): Interleukin 17 of the three studied groups:

\begin{tabular}{|c|c|c|c|c|c|}
\hline Variable & $\begin{array}{c}\text { Control } \\
(n=27)\end{array}$ & $\begin{array}{c}\text { Group } 1 \\
(n=27)\end{array}$ & $\begin{array}{c}\text { Group } 2 \\
(n=27)\end{array}$ & $\begin{array}{c}\text { ANOVA } \\
\text { test }\end{array}$ & $\mathbf{P}$ \\
\hline $\begin{array}{l}\text { Interleukin 17: } \\
\text { Mean } \pm S D \\
\text { Range }\end{array}$ & $\begin{array}{c}79.81 \pm 12.38 \\
49-99\end{array}$ & $\begin{array}{c}197.15 \pm 71.36 \\
69-319\end{array}$ & $\begin{array}{c}296.96 \pm 99.22 \\
133-477\end{array}$ & 63.41 & $0.000 * *$ \\
\hline $\begin{array}{l}\text { Control Group } \\
\text { Control Group } \\
\text { Group } 1 \text { versus }\end{array}$ & $\begin{array}{l}\text { us Group } 1 \\
\text { us Group } 2 \\
\text { ip } 2\end{array}$ & & & & $\begin{array}{l}0.000 * * \\
0.000 * * \\
0.000 * *\end{array}$ \\
\hline
\end{tabular}

This table shows that there were statistical significance differences $(\mathrm{P}<0.001)$ between the three studied group in interleukin 17 level. The highest mean of IL 17 level were found in group 2 followed by group 1 and the control group had the lowest mean level.

Table 2: Relation between Child score and interleukin 17 level of the two patients studied groups:

\begin{tabular}{|c|c|c|c|c|c|}
\hline \multirow[t]{2}{*}{ Variable } & \multicolumn{3}{|c|}{ Child score } & \multirow[t]{2}{*}{$\mathbf{F}$} & \multirow[t]{2}{*}{$\mathbf{P}$} \\
\hline & $\mathbf{A}$ & $\mathbf{B}$ & $\mathbf{C}$ & & \\
\hline Group 1: & $(n=8)$ & $(n=9)$ & $(n=10)$ & & \\
\hline$M e a n \pm S D$ & $113.62 \pm 28.75$ & $195.40 \pm 30.13$ & $270 \pm 33.45$ & 56.73 & $\mathbf{0 . 0 3} *$ \\
\hline Range & $69-145$ & $136-240$ & $212-319$ & & \\
\hline Group 2: & $(n=8)$ & $(n=9)$ & $(n=10)$ & & \\
\hline$M e a n \pm S D$ & $171.83 \pm 19.50$ & $299.44 \pm 36.86$ & $395.20 \pm 46.78$ & 80.44 & $0.006 * *$ \\
\hline Range & $133-190$ & $230-333$ & $340-477$ & & \\
\hline
\end{tabular}

This table shows that there were statistical significance differences between Child score A, B and C in both group 1 and group 2 in IL 17 level with the highest level in C cases. 
Table 4:Relation between number of tumors and interleukin 17 level of the group 2:

\begin{tabular}{lcccc}
\hline \multicolumn{1}{c}{ Variable } & \multicolumn{3}{c}{ HCC } & T \\
\cline { 2 - 3 } & Single & Multiple & P \\
\hline Group 2: & $(\mathrm{n}=18)$ & $(\mathrm{n}=9)$ & \\
Mean $\pm S D$ & $311.28 \pm 96.66$ & $268.33 \pm 103.72$ & 1.06 & 0.30 \\
Range & $155-477$ & $133-440$ & N.S
\end{tabular}

This table showed that there were no statistical significance differences between cases with single tumors and cases with multiple tumors in its level.

Table 5 : Tumor diameter and its Correlation interleukin 17 level:

\begin{tabular}{llclc}
\multicolumn{1}{c}{ Variable } & Mean \pm SD & Range & r & P \\
\hline Tumor diameter & $3.80-58.74$ & $19.98 \pm 15.33$ & 0.20 & 0.32
\end{tabular}

This table shows that IL17 level in group 2 hadn't correlation with tumor diameter.

Table 6 :Correlation between Laboratory finding and interleukin 17 of the three studied groups:

\begin{tabular}{|c|c|c|c|c|c|c|}
\hline \multirow[t]{2}{*}{ Variable } & \multicolumn{2}{|c|}{$\begin{array}{c}\text { Control } \\
(n=27)\end{array}$} & \multicolumn{2}{|c|}{$\begin{array}{c}\text { Group } 1 \\
(n=27)\end{array}$} & \multicolumn{2}{|c|}{$\begin{array}{c}\text { Group } 2 \\
(n=27)\end{array}$} \\
\hline & $\mathbf{r}$ & $\mathbf{P}$ & $\mathbf{r}$ & $\mathbf{P}$ & $\mathbf{r}$ & $\mathbf{P}$ \\
\hline WBCs & 0.28 & 0.16 & -0.31 & 0.12 & -0.47 & $0.01 *$ \\
\hline $\mathrm{Hb}$ & 0.18 & 0.38 & -0.09 & 0.66 & -0.23 & 0.24 \\
\hline Platelets & 0.12 & 0.31 & -0.06 & 0.76 & -0.19 & 0.34 \\
\hline PTT & 0.27 & 0.17 & 0.48 & $0.01 *$ & 0.15 & 0.45 \\
\hline Bilirubin & 0.06 & 0.75 & 0.91 & $0.000 * *$ & 0.82 & $0.000 * *$ \\
\hline ALT & 0.07 & 0.74 & -0.14 & 0.37 & -0.26 & 0.20 \\
\hline AST & -0.12 & 0.54 & 0.08 & 0.68 & -0.06 & 0.77 \\
\hline Albumin & -0.20 & 0.31 & -0.94 & $0.000 * *$ & -0.89 & $0.000 * *$ \\
\hline Creatinin & -0.21 & 0.31 & 0.18 & 0.36 & 0.14 & 0.49 \\
\hline INR & 0.11 & 0.58 & 0.88 & $0.002 * *$ & 0.83 & $0.001 * *$ \\
\hline$\alpha$ fetoprotein & -0.06 & 0.76 & 0.65 & $0.005 *$ & 0.78 & $0.004 *$ \\
\hline
\end{tabular}

This table shows that IL17 level in control group hadn't correlation with any of Lab. findings. But in both group1 and group2 IL17 level had +ve significant correlations with bilirubin, INR and $\alpha$ fetoprotein and -ve correlation with albumin. In group1 IL17 had +ve significant correlation with PTT. Finally in group2 there was +ve significant correlation between IL17 and WBCs count. 


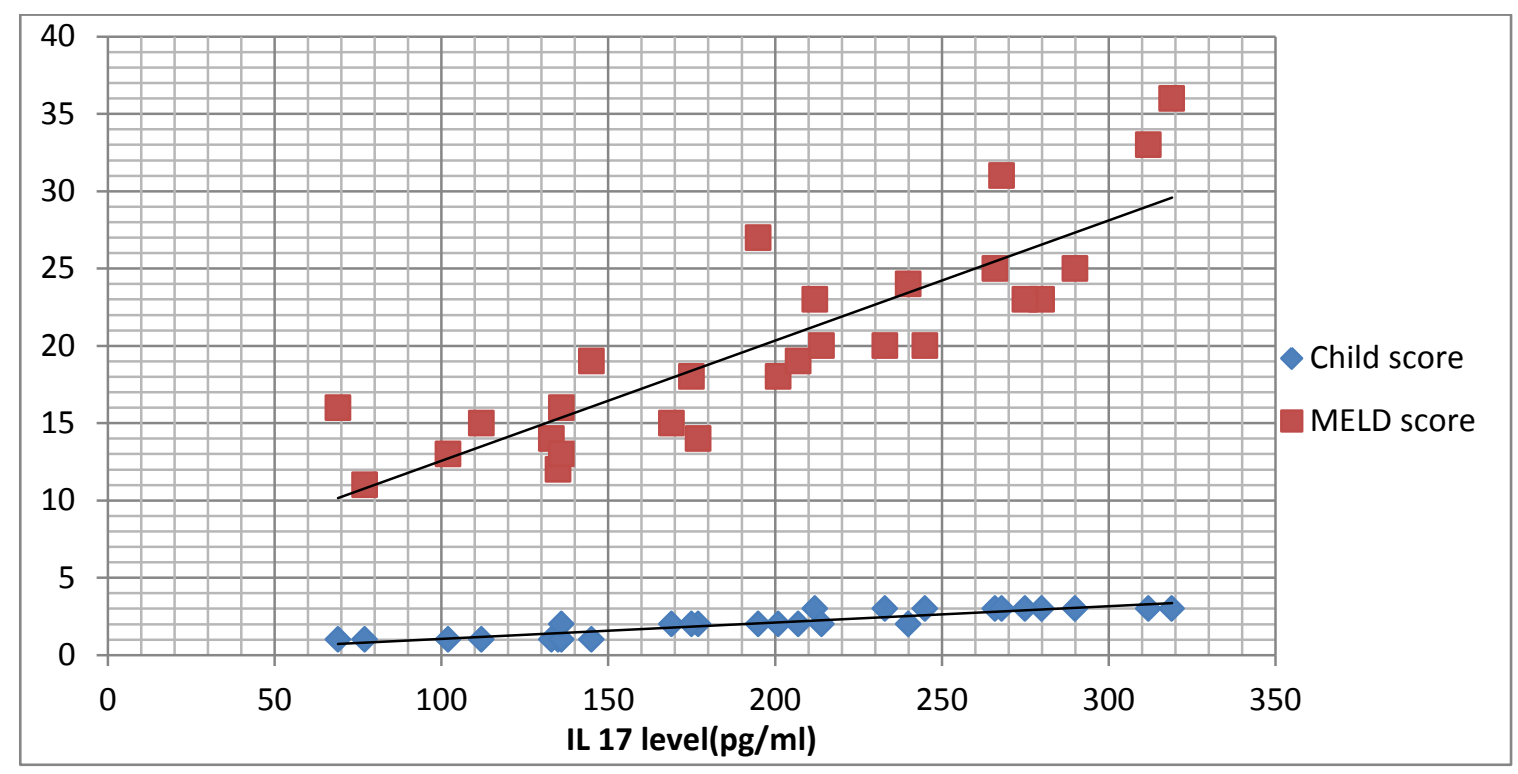

Figure(1) shows positive correlation between IL 17 and both Child \& MELD score in Group1.

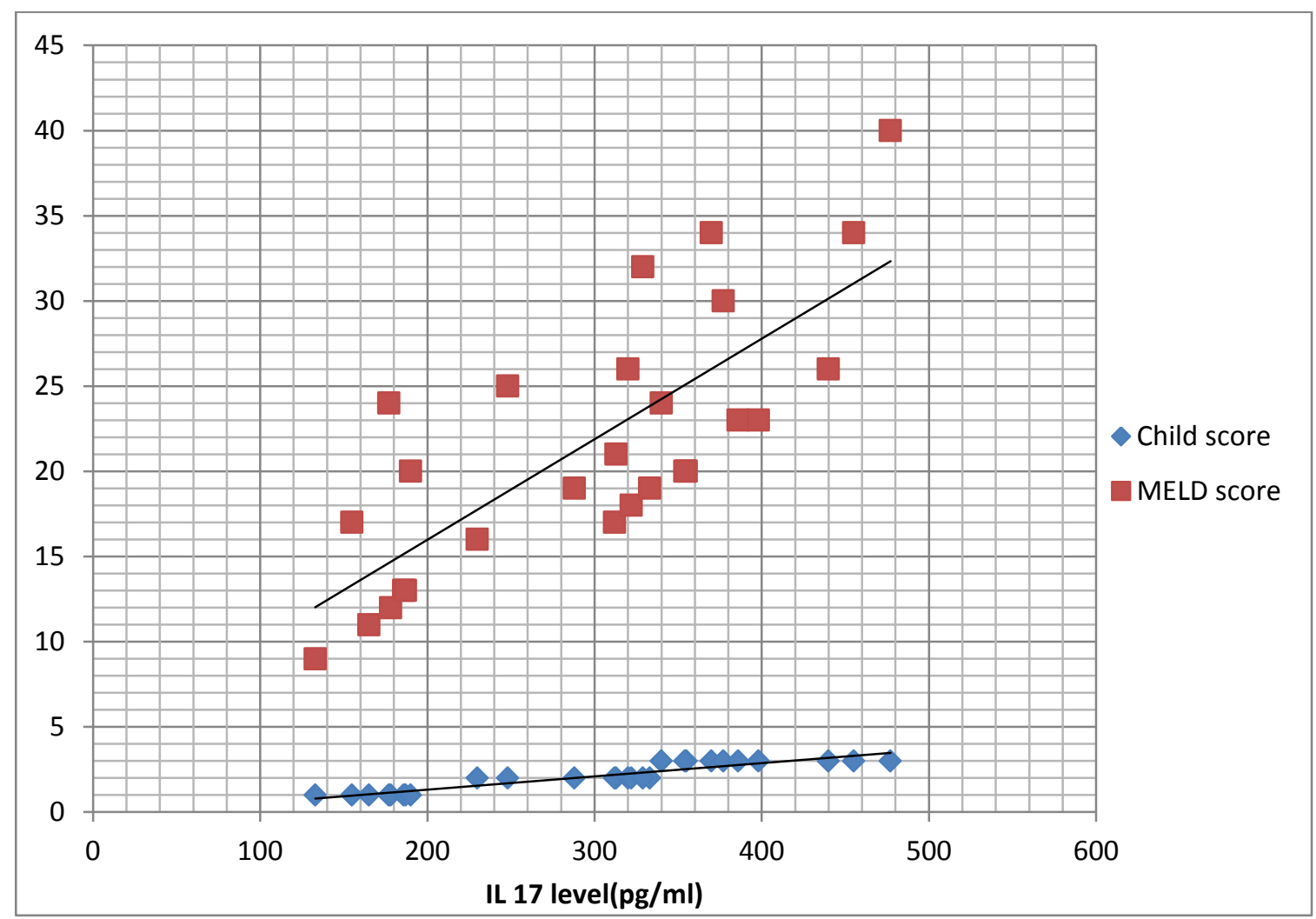

Figure(2) shows positive correlation between IL 17 and both Child \& MELD scores in Group2. 


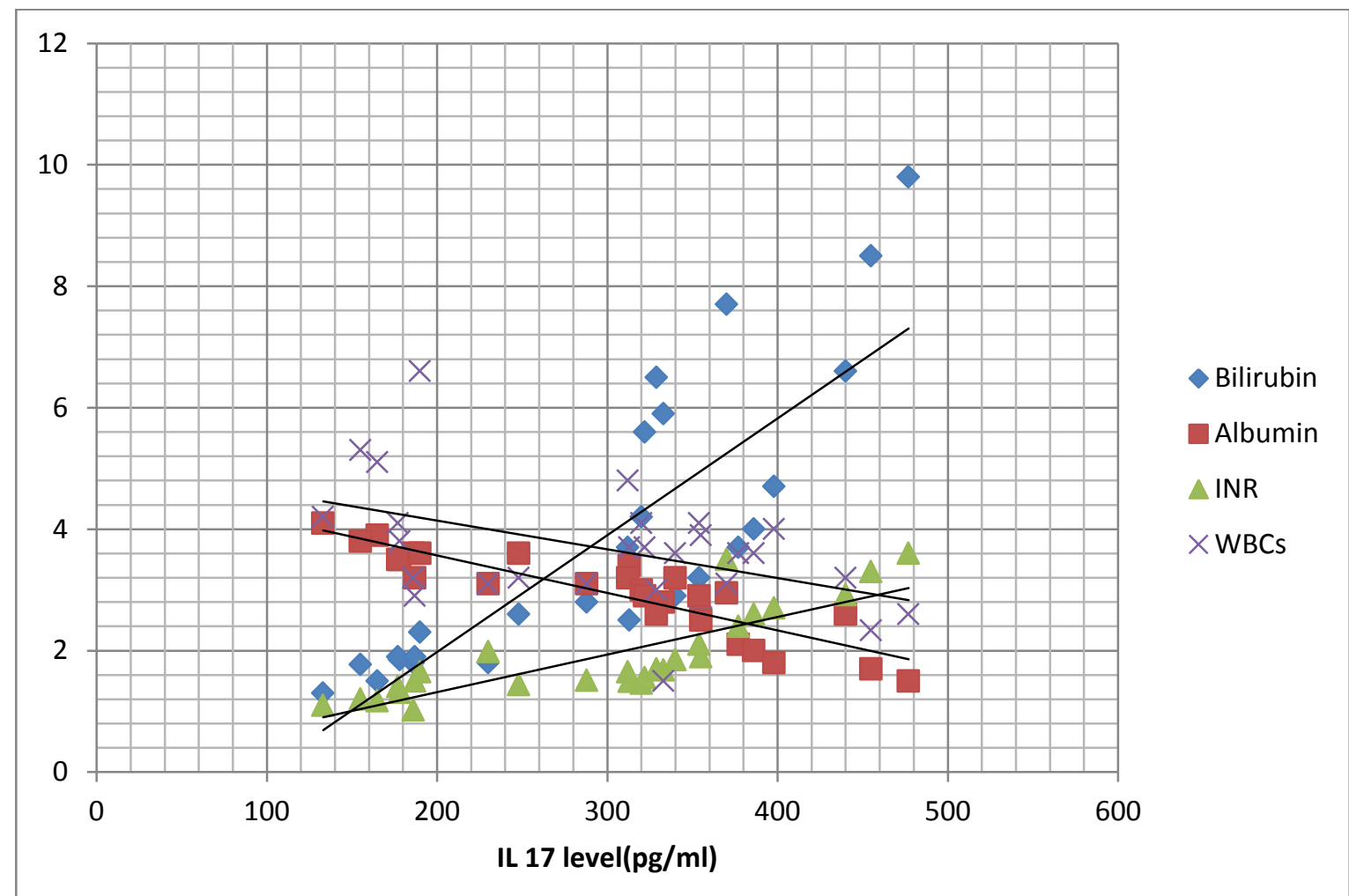

Figure (3): Correlations between IL17 and lab. findings in group2.

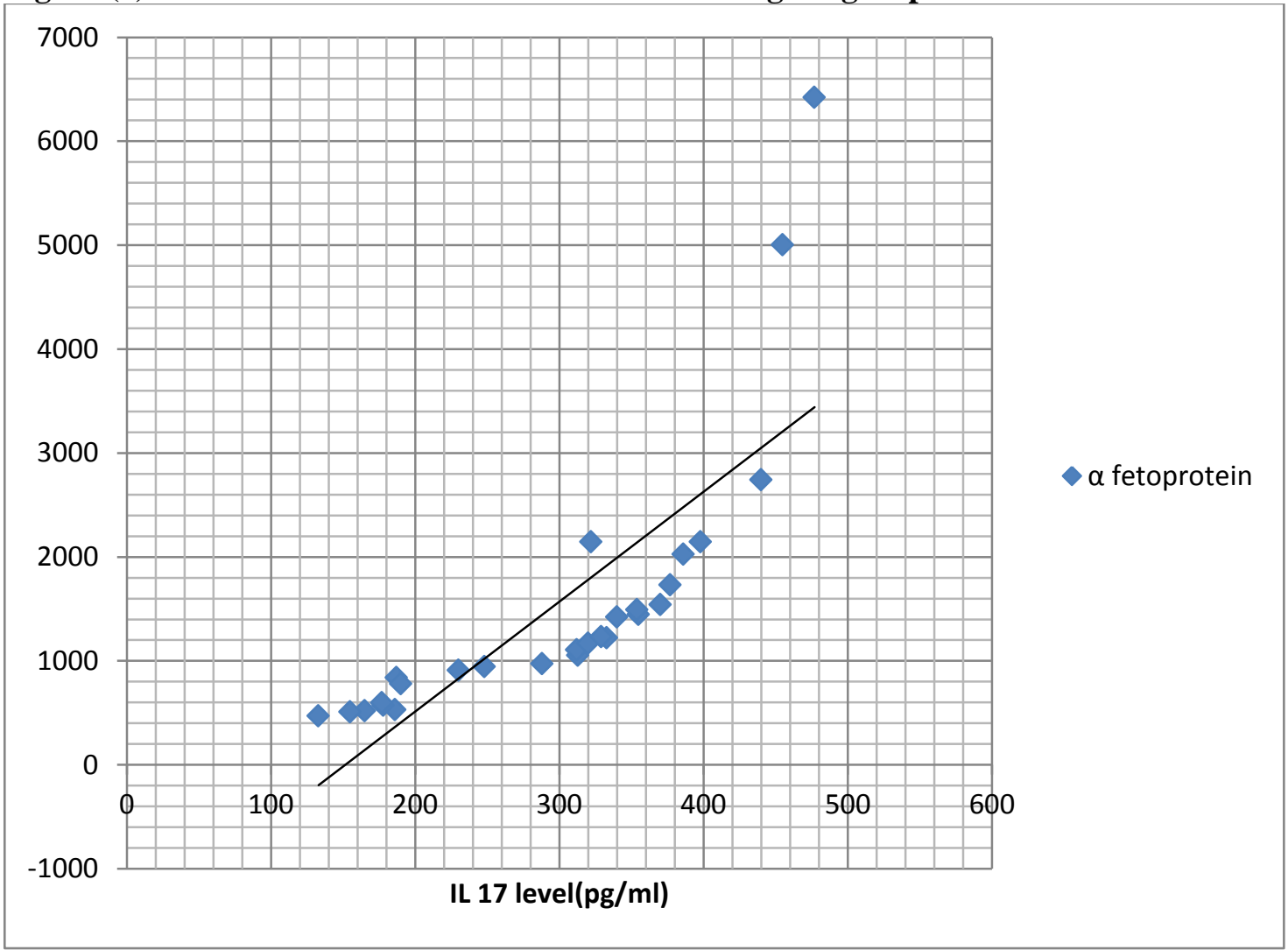

Figure (4): Correlations between IL17 and a fetoprotein in group2 


\section{DISCUSSION}

Hepatocellular carcinoma (HCC) is the $5^{\text {th }}$ most frequently diagnosed cancer and the $2^{\text {nd }}$ most common cause of cancer death worldwide [13] . HCC accounts for approximately 600,000 deaths annually ${ }^{[14]}$. Worldwide, HCV accounts for a $25 \%$ of cases ${ }^{[15]}$. In the Egyptian population, up to $90 \%$ of $\mathrm{HCC}$ cases were attributed to $\mathrm{HCV}$ infection ${ }^{[3]}$.

Cirrhosis secondary to $\mathrm{HCV}$ is associated with the highest annual risk for developing HCC. Annual incidence rates of HCC in patients with HCV-related cirrhosis range widely from $1 \%$ to $8 \%{ }^{[16]}$.

In HCV infected patients IL-17 is produced through recognition of viral pathogenassociated molecular pattern (PAMP) such as Toll-like receptor (TLR)3 ligands ${ }^{[17]}$. Also the increased number of Th17 cells appears to be associated with the severity of liver inflammation in chronic HCV patients ${ }^{[18]}$.

Moreover, it has been reported that intrahepatic IL-17 expression was positively correlated with the serum indices of hepatic fibrosis that is an important pathological process in the development of liver cirrhosis. ${ }^{[19]}$.

Therefore, the aim of our study was to clarify the role of IL17 in hepatocellular carcinoma in end stage liver disease in $\mathrm{HCV}$ infected patients.

We demonstrated statistical significance differences between the three studied groups in interleukin 17 level. The highest mean of IL 17 level were found in group 2 with Mean \pm SD $296.96 \pm 99.22$ followed by group 1 with Mean \pm SD $197.15 \pm 71.36$ and the control group had the lowest mean level with Mean \pm SD $79.81 \pm$ 12.38. These results go with that reported by Chang $Q$ et al., $2012^{[20]}$, Hassan EA et al., $\mathbf{2 0 1 4}^{[21]}$ and Shi et al., 2015 ${ }^{[22]}$ described high level of IL17 in cirrhotics and higher in HCC patients

Seetharam et al., 2011 described different results; a transient IL-17 and IL-10 response may also result in spontaneous viral clearance followed by a subsequent reactivation of Th1 immunity, which prevented relapse. Therefore, IL-17 and Th17 cells may play an important role in viral clearance. But these results were from patients after liver transplantation while our study was conducted on cirrhotic patients with or without $\mathrm{HCC}^{[23]}$.
Our study demonstrated positive correlation between IL 17 with Child score A, B and $\mathrm{C}$ in both group 1 and group 2 in with the highest level in $\mathrm{C}$ classes. In agreement with Ghazy NA et al., $2013^{[24]}$ and Shi et al., 2015. ${ }^{[22]}$ IL-17A has critical role in the pathogenesis of liver fibrosis. IL-17A produced by neutrophils and $\mathrm{CD} 4+\mathrm{T}$ and $\mathrm{CD} 8+$ cells promoted proinflammatory cytokine expression, neutrophil influx, liver injury, inflammation, and fibrosis through Hepatic Stellate Cell Activation. There is increased level of IL17 with increasing inflammation, fibrosis and cirrhosis. ${ }^{[25]}$ While Hassan EA et al., 2014 reported no correlation between Child score and IL17 level . ${ }^{[21]}$

As regard the relation between symptoms \& signs and interleukin 17 level of the three studied groups we demonstrated that there was no statistical significance difference between cases with upper GIT bleeding and cases without in interleukin 17 level in both group1 and group2.

But there were statistical significance differences between cases had jaundice, encephalopathy and ascites and cases hadn't in IL 17 level in both group1 and group 2. Shi et al., 2015 correlated IL17 with liver inflammation, necrosis and synthesis function, suggesting an important function in the occurrence and development of liver fibrosis . ${ }^{[22]}$ Which are the main cause of jaundice, encephalopathy and ascites.

Our study showed that there were no statistical significance differences between cases with single tumors and cases with multiple tumors in level of IL17 going in line with the results of Liao $\mathbf{R}$ et al., 2013. Also, he reported that high expression of IL-17 and IL-17RE associate with poor prognosis of hepatocellular carcinoma ${ }^{[26]}$. Our study was in accordance with Wu et al., 2012 ${ }^{[27]}$ where the increased serum IL-17 level was not significantly influenced by the tumor intrinsic characteristics (tumor size and number). The contribution of IL-17 and Th17-related immunity during carcinogenesis has been demonstrated recently . [26] The potential mechanisms involve angiogenesis and promotion of tumor growth by cytokine induction in the tumor microenvironment and activating the oncogenic signal Stat3. ${ }^{[28]}$

IL 17 was negatively correlated with white blood cells count in agreement with Qi W., 2014 
[29] which can describe deterioration in the immune status.

Bilirubin and INR were positively correlated with IL 17 level while albumin was negatively correlated in group 1 and group 2 in accordance with Shi $\mathbf{M}$ et al., 2015. ${ }^{[2]}$ This is probably because IL-17 activates a variety of immune cells to release inflammatory mediators, leading to repeated inflammation of the liver and deterioration of liver function . ${ }^{[30]}$

ALT and AST levels showed no correlation with IL 17 level going in line with that reported by . Ghazy NA et al., $\mathbf{2 0 1 3}^{[24]}$ and Hassan EA et al., 2014 ${ }^{[21]}$ and in contradictory to that reported by Shi M et al., $\mathbf{2 0 1 5}^{[22]}$ as the ALT and AST levels may be affected by drug intake.

$\alpha$ fetoprotein was positively correlated with IL 17 level in group1 and group $2(\mathrm{p}<0.05)$. Which is compatible with results of Ghazy NA et al., 2013 ${ }^{[24]}$ and not compatible with that reported by Liao $\mathbf{R}$ et al., 2013. ${ }^{[26]}$

\section{CONCLUSION}

We can conclude that IL-17 levels were increased with increasing progression of liver disease. Also, the elevation of IL-17 level with HCC suggest immunopathogenic role in the development of HCC. So, with the advance of IL-17 antagonists we recommend their use experimentally in the treatment of $\mathrm{HCC}$ in animals to assess the possibility of its use in human. But, care must be taken as IL-17 has great role in immunity against bacterial and fungal infections.

\section{REFERENCES}

1.El-Serag HB1 and Rudolph KL (2007) "Hepatocellular carcinoma: epidemiology and molecular carcinogenesis". Gastroenterology132(7) : 2557-76.

2.El-Zayadi AR, Badran HM, Barakat EM, et al (2005) "Hepatocellular carcinoma in Egypt: a single center study over a decade". World J Gastroenterol 11(33):5193-8.

3.Ezzat S, Abdel-Hamid $M$ and Eissa SA (2005) "Associations of pesticides, HCV, $\mathrm{HBV}$, and hepatocellular carcinoma in Egypt". Int J Hyg Environ Health208: 32939.

4.Goldman R., Ressom H., Goldman L., et al (2009) "Detection of Hepatocellular Carcinoma Using Glycomic Analysis". Clin Cancer Res15: 1808-13.
5.Dustin LB and Rice CM. (2007) "Flying under the radar: the immunobiology of hepatitis C". Annu Rev Immunol25:71-99

6.Smyk-Pearson S, Tester IA, Klarquist J, et al (2008) "Spontaneous recovery in acute human hepatitis $\mathrm{C}$ virus infection: functional T-cell thresholds and relative importance of CD4 help". J Virol 82:1827-1837

7.LeibundGut-Landmann S, Gross O, Robinson MJ, et al (2007) "Syk- and CARD9dependent coupling of innate immunity to the induction of $\mathrm{T}$ helper cells that produce interleukin17”. Nat Immunol 8:630-638

8.Rong G, Zhou Y, Xiong Y, et al (2009) "Imbalance between $\mathrm{T}$ helper type 17 and $\mathrm{T}$ regulatory cells in patients with primary biliary cirrhosis: the serum cytokine profile and peripheral cell population". Clin Exp Immunol 156:217-225

9.Kryczek I, Banerjee M, Cheng P, et al (2009) "Phenotype, distribution, generation, and functional and clinical relevance of Th17 cells in the human tumor environments". Blood 114:1141-1149

10.Murugaiyan G and Saha B (2009) "Protumor vs antitumor functions of IL-17'. J Immunol. 183(7):4169-75.

11.Numasaki M, Fukushi J, Ono M, et al (2003) "Interleukin-17 promotes angiogenesis and tumor growth". Blood 101(7):2620-27

12.Zúñiga LA, Shen WJ, Joyce-Shaikh B, et al (2010) "IL-17 regulates adipogenesis, glucose homeostasis, and obesity". J Immunol. 185(11):6947-59.

13.Jemal A, Bray F, Center MM, et al (2011) "Global cancer statistics". CA: a Cancer Journal for Clinicians 61(2):69-90

14.El-Serag HB (2004) "Hepatocellular carcinoma: Recent trends in the united states". Gastroenterology 127(5, Suppl 1):S27-S34

15.Sanyal AJ, Yoon SK, Lencioni R, et al (2010)"The etiology of hepatocellular carcinoma and consequences for treatment". Oncologist 15(Suppl 4):14-22

16.El-Serag HB (2012) "Epidemiology of viral hepatitis and hepatocellular carcinoma". Gastroenterology 142(6):1264-1273

17.Tanaka J, Watanabe N, Kido M, et al (2009) "Human TSLP and TLR3 ligands promote differentiation of Th17 cells with a central memory phenotype under Th2-polarizing conditions". Clin Exp Allergy 39:89-100. 
18.Foster RG, Golden-Mason L, Rutebemberwa A, et al ( 2012) "Interleukin (IL)-17/IL-22producing $\mathrm{T}$ cells enriched within the liver of patients with chronic hepatitis $\mathrm{C}$ viral $(\mathrm{HCV})$ infection". Dig Dis Sci 57:381-389

19. Woltman AM, Haij S, Boonstra JG, et al (2000) "Interleukin-17 and CD40-ligand synergistically enhance cytokine and chemokine production by renal epithelial cells". J Am Soc Nephrol 11: 2044-2055

20.Chang Q, Wang YK, Zhao Q, et al (2012) "Th17 cells are increased with severity of liver inflammation in patients with chronic hepatitis C'. J Gastroenterol Hepatol 27: 273-278

21.Hassan EA, Abd El-Rehim AS, Ahmed AO, et al (2014) "The Impact of Serum Interleukin-17 on Chronic Hepatitis $\mathrm{C}$ and Its Sequelae". J Liver 3: 163.

22.Shi M, Wei J, Dong J, et al (2015)“Function of interleukin-17 and-35 in the blood of patients with hepatitis B-related liver cirrhosis" MOLECULAR MEDICINE REPORTS 11: 121-126

23. Seetharam AB, Borg BB and Subramanian V ( 2011) "Temporal association between increased virus specific TH17 response and spontaneous recovery from recurrent hepatitis C in a liver transplant recipient". Transplantation 92(12):1364-70

24.Ghazy NA ,Okasha HS ,El Khouly EH, et al (2013) "Quantitative Estimation of
Interleukin-17 in Patients with Chronic Liver Disorders". J Am Sci 9(1):329-337

25.Tan Z, Qian X, Jiang R, et al (2013) "IL-17A Plays a Critical Role in the Pathogenesis of Liver Fibrosis through Hepatic Stellate Cell Activation" jimmunol.1203 013

26.Liao R, Sun J, Wu H, et al (2013) "High expression of IL-17 and IL-17RE associate with poor prognosis of hepatocellular carcinoma”. J Exp Clin Cancer Res 32: 3

27.Wu J, Du J, Liu L, et al (2012) "Elevated pretherapy serum IL17 in primary hepatocellular carcinoma patients correlate to increased risk of early recurrence after curative hepatectomy". PLoS One 7(12):e50035.

28.Ye J, Livergood RS, Peng G et al (2013) "The role and regulation of human Th17 cells in tumor immunity". Am J Pathol 182:10-20

29.Qi W, Fu R, Wang $H$, et al (2014) "Association between serum interleukin-17 level and abnormal cellular immunological status in patients with severe aplastic anemia". Zhonghua Yi Xue Za Zhi 94(20):1539-42

30.Harada K, Shimoda S, Sato Y, et al (2009) "Periductal interleukin-17 production in association with biliary innate immunity contributes to the pathogenesis of cholangiopathy in primary biliary cirrhosis". Clin Exp Immunol 157: 261-270. 